\title{
APRECIACIONES SOBRE EL PARO FORZOSO
}

\author{
Por Pablo CHUECA REMON
}

\begin{abstract}
1) Consideraciones preliminares. - 2) Causas del fenómeno. - 3) Definición. - 4) Clases de desocupados. - 5) Formas de paro. - 6) Importancia y trascendencia mundiales del problema.
\end{abstract}

Aun para el profano en cuestiones relativas al trabajo, el paro forzoso o desocupación, es tema que cautiva necesariamente su atención; y es explicable que así suceda, pues los gravísimos problemas que crea a la sociedad la aparición de tan temido mal, justifican fácilmente la convergencia del interés público en tan apasionante asunto. En este artículo en el que no hay pretensión alguna de originalidad, pero sí de simple di.. vulgación- trataremos de enfocar el tema desde el punto de vista del Derecho del Trabajo, reservándonos para uń artículo posterior desenvolver otros puntos del mismo.

Según la experiencia histórica, el hombre ha debido trabajar siem pre para poder, subsistir. No vamos ahora a detenernos a establecer si el trabajo es o no necesario - desde un plano teórico por cierto- para que el hombre pueda atender a la satisfacción de sus necesidades vitales, pues lo que interesa es lo real, lo que a través de los siglos ha existido y lo que la experiencia de nuestra vida y la de nuestros semejantes nos está demostrando, esto es, que el hombre ha tenido, en todas las épocas, que procurarse el sustento merced a su trabajo. (1)

El hombre, en consecuencia, se ve obligado a trabajar para no sucumbir y desaparecer de la faz de la Tierra. Pero, aquí surge el problema que nos ocupa: ¿basta que el hombre quiera trabajar para tener asegurada su supervivencia? Desgraciadamente la respuesta es negativa. Hay períodos en la vida de la Humanidad en que no obstante la voluntad de trabajar del hombre, no halla cómo hacerlo, y es entonces cuando surge el pavoroso fantasma de la desocupación, determinante en muchos casos de grandes tragedias colectivas. En los tiempos primitivos el hombre, valido de sus manos y de instrumentos rudimentarios, se procura el sustento para sí y para quienes dependen de él; en esa época no existe, pues, desocupación. Pero la especie humana, a través de los siglos, se reproduce y crece hasta alcanzar la cifra aproximada de 2.000 millonęs de seres que hoy 
viven en nuestro planeta, y con tal crecimiento y desenvolvimiento en todo género de actividades, llegamos a la era del maquinismo, del trabajo altamente diferenciado y de las zonas industriales densamente pobladas, en donde no siempre el hombre encuentra ocupación. Es entonces cuando surge el fenómeno del desempleo. El trabajador por sí solo, únicamente con su cerebro y sus brazos, no siempre puede crear trabajo que lo capacite para adquirir los bienes necesarios que habrán de satisfacer sus necesidades cotidianas; es menester, en la mayoría de los casos, que se le ofrezca lo que busca: una oportunidad para trabajar, una fuente de trabajo, y este cometido es el que realiza la persona física o jurídica del empleador, al facilitarle los medios de trabajar y en dónde hacerlo. Sin el aporte del empleador, el trabajador tendría que permanecer cruzado de brazos, sin poder ganarse el sustento, ya que no dispondría de bien alguno con valor de cambio en el mercado. Es obvio, entonces, que toda vez que el trabajador no pueda contar con la oportunidad de trabajar, ya sea que él la demande o que se la ofrezcan, quedará en la situación de parado forzoso. ¿ $Y$ por qué se da esta situación de ausencia de colaboración en el empleador? Bueno; la explicación de este fenómeno es, precisamente, la explicación de la razón determinante del paro forzoso. Esta causa determinante está constituída por diversos élementos, contándose entre ellos, como factor preponderante, la crisis económica. Siempre que el poder de consumo no marcha acorde con la capacidad de producción, se produce un desequilibrio económico que genera el paro forzoso, pues ocurre que como lo producido cubre con creces la demanda en el mercado, es necesario dejar de producir durante un lapso para que sobrevenga el equilibrio, y al dejar de producir se deja desocupadas a grandes masas de trabajadores. La causa primigenia, por consiguiente, es la crisis económica; pero no es la única porque también existen causas concurrentes, como la deficiente coordinación del trabajo, la carencia de escuelas de orientación vocacional, la deficiente distribución de las industrias cuando genera la afluencia de trabajadores especializados en una misma rama industrial a determinadas zonas, la excesiva duración de la jornada de trabajo, las migraciones orientadas hacia regiones en donde no son necesarias, la deficiente manera de cultivo en la agricultura, El tratadista chileno Francisco W/alker Linares (2) anota estas otras causas: a) Superproducción excesiva, por una parte, debido al adelanto de la técnica y a la racionalización, y por otra parte subconsumo, por falta de poder adquisitivo de las masas consumidoras; b) Maquinismo exagerado, que produce el desplazamiento del hombre por la máquina; c) Nacionalismo excesivo, que trastorna los mercados, impidiendo que artículos producidos en abundancia en ciertos países tengan ingreso a otros que los necesitan imperiosamente, todo ello sólo con el fin de crear industrias artificiales, protegidas a su vez por barreras aduaneras asimismo artificiales, con la finalidad de conquistar la utópica autarquía; d) Trastornos monetarios que disminuyen el poder de compra de muchos Estados a causa de la depreciación de las monedas, o. bra de la inflación, e impiden la libre circulación de los productos; y e) Exceso de créditos, con lo cual se aumenta exageradamente la producción sin atender a las necesidades de consumo. A estas causas económicas es menester sumar las políticas y morales, que sobre todo se patentizan en esta época de incertidumbre y desasosiego por que atraviesa la Humanidad. Las consideraciones precedentes permiten, entonces, formarnos ya 
una idea de lo que es la desocupación. El profesor español García Oviedo (3) define el paro forzoso en los siguientes términos: "Se entenderá por paro forzoso el producido por causas ajenas a la voluntad del parado que no encuentra una ocupación adecuada a su trabajo habitual, con exclusión, por tanto, del que se deriva de incapacidad física del obrero (accidente, enfermedad común o profesional, invalidez y vejez) y de los conflictos del trabajo (huelga y paro patronal)". Ramírez Gronda, Catedrático en la Universidad de La Plata, (4) coincide con este concepto al definir al parado como "el obrero que no trabaja porque no existe demanda de la mano de obra". En consecuencia, para afirmar que un trabajador está desocupado, es menester que se encuentre en aptitud y poseído de la voluntad de trabajar y que, sin embargo, no halle ocupación. Por lo tanto, el individuo que no puede trabajar, no porque no halla trabajo sino porque alguna enfermedad, un accidente o la invalidez o la vejez se lo impiden. no debe ser considerado parado involuntario. Además, la pérdida de un empleo ocasional, el cese en una actividad que no es la propia (como el caso de obreros industriales que pretendieron encontrar ocupacion en labóres de comercio) no puede considerarse como paro forzoso, pues estos hombres, dedicándose a sus ocupaciones habituales, pueden hallar oportunidad de trabajar, debiendo considerárseles parados forzosos únicamente en el caso de no obtener trabajo en dicha actividad propia.

Hoy puede distinguirse hasta cuatro clases de desocupados: $1{ }^{\circ}$, los obreros y empleados, quienes están comprendidos en la denolninación general de trabajadores; $2^{\circ}$, los desocupados intelectuales (profesionales, maestros, artistas, etc.); $3^{\circ}$, los trabajadores independientes sin trabajo, tales como artesanos; y $4^{\circ}$, los desocupados de países extraños a la civilización occidental, como los de India, China y otros países asiáticos, que no están comprendidos en las estadísticas (Walker Linares, ob. cit).

La desocupación involuntaria o paro forzoso, puede ser completa o también parcial (5). Es completa en el parado que ha sido desahuciado y a quien no lo liga contrato de trabajo alguno con su principal y es parcial en el trabajador que mantiene indemne su contrato de trabajo, pero con labor disminuída. Hay, además, otra modalidad de paro forzoso: la temporal, esto es, aquella en que está comprendido el trabajador que es despedido con promesa de ser empleado nuevamente dentro de algún tiempo. En cuanto al paro parcial, éste presenta generalmente tres aspectos: a) reducción del número de horas diarias; b) disminución de las jornadas semanales; y c) trabajo por turnos, con una semana o dos de labor, alter. nadas con otras tantas de desocupación. La desocupación parcial es, por cierto, un mal menor; pero si se hace crónico, si su duración es extremada, se convierte en buena cuenta en un "short time" que determina un descenso en la suma de ganancias de los asalariados y el subsiguiente desequili. brio en sus presupuestos familiares, cuando no genera una situación de franca miseria.

Las formas de paro anteriormente expuestas se dan en la industria; pero también en la agricultura se presenta el fenómeno que estudiamos con las siguientes características: paro ocasional, que es el producido como consecuencia de una mala cosecha o de condiciones atmosféricas especialmente favorables que disminuyen la demanda habitual de mano de obra para la siega y otras labores, siendo esta modalidad, por su naturaleza, de carácter local; el paro estacional es, por lo contrario, endémico y 
tiene su origen en la característica de la producción agrícola: la de ser estacional, y es por ello que no hay trabajo durante todo el año sino en determinadas épocas; además, el paro estacional tiende a hacerse más extenso en razón directa a la introducción de la máquina (como sucede en ei caso de la trilladora) que elimina la labor de muchos hombres. En los países altamente industrializados el trabajador agrícola, sin emigrar a regiones distantes o mediante desplazamientos de poca extensión, puede hallar trabajo en la industria cuando no lo obtiene en la agricultura, pero en nuestro país no ocurre fácilmente esa situación; sin embargo, cuando en las épocas de cosecha en la Costa vienen de la Sierra grandes masas de trabajadores (como sucede en las haciendas azucareras del Norte de la República) no surge entre ellos el fenómeno del paro estacional porque terminada aquella retornan a sus lugares de origen. Finalmente, el sub empleo es otra de las formas de paro en la agricultura, y se denomina así al período - que puede ser de días, semanas y hasta meses- en que, por exceso de población agrícola o por deficiente desarrollo de la agricultura, núcleos de trabajadores de los campos quedan sin ocupación.

$$
* * *
$$

La importancia mundial y trascendencia incalculable del fenómeno del paro forzoso no data de ahora; ya Carlyle decía que "en el cuadro de las miserias imaginables nada hay más doloroso ni excitador de la conciencia humana como el hecho de un hombre que, por huir del hambre, busca trabajo y no lo encuentra". Hasta se ha llegado a afirmar - según lo hizo el Diputado francés Vaillant- que la revolución de 1830 se debió al paro forzoso de los impresores y la de 1848 en las calles de París a los desocupados del terrible invierno de ese año. El paro forzoso, como observamos, siempre ha existido; es un mal endémico en el régimen capitalista de la sociedad, y las estadísticas nos demuestran dicho carácter, pues en el perícdo comprendido entre 1896 y 1901 existían en los principales países industriales de aquel entonces: Francia, Alemania e Inglaterra, un porcentaje de desocupados entre la población asalariada en la industria y el comercio, ascendente a 5,7, y 5 por ciento, respectivamente. Estas le. giones de desocupados en Europa, fueron las que hicieron exclamar a Marx que constituían "la reserva del ejército activo del trabajo". Pero el paro forzoso, en ciertas épocas, abandona su carácter de dolencia social crónica para agudizarse y trocarse en azote despiadado de la Humanidad. Tal aconteció en el período comprendido entre los años 1929 y 1934, época de intensa desocupación; período durante el cual la cifra de trabajadores desocupados en el Mundo ascendía a más de treinta millones (6). Después de 1934, en parte por ciertas medidas como la reducción de la jornada de trabajo y otro tanto por el resurgimiento industrial -producto en mucho de la carrera armamentista de las grandes potencias- el paro ha retornado a sus cauces normales, esto es a su situación de mal endémico; pero siempre existe, pese al consumo de hombres que demanda la guerra actual, y se mantiene perennemente como una amenaza latente contra la estabilidad social. Y prueba de esta amenaza latente nos la dió el señor Henry A. Wallace, cuando en su carácter de Vicepresidente de los 
Estados Unidos de América declaró entre otras cosas, al dar término a su viaje a estos países en abril de 1943, que había palpado en las clases trabajadoras, sobre todo en las que laboran en industrias intimamente ligadas a fines bélicos, como la minería por ejemplo, la ansiedad que las dominaba a! pensar en que, si una vez terminada esta guerra mundial, tendrían o no que hacerle frente al temible monstruo del desempleo, agregando el citado hombre público de la Unión: "Los trabajadores destacan que están produciendo todo lo posible para contribuir al esfuerzo de guerra, pero después se preguntan: ¿qué nos pasará cuando llegue la paz?".

Existe, pues, tanto en las clases dirigentes cuanto en las trabajado. ras, el firme y decidido propósito de enfrentarse á los peligros que entraña la desocupación y a combatirla por todos los medios para evitar que cunda en el Mundo al finalizar la presente Conflagación. Y de estos medios y de los que se han llevado a la práctica hasta ahora, nos ocuparemos en un próximo artículo.

(1).--Respecto a la discusión doctrinaria sobre la necesidad del trabaja como medio de subsistencia, recomendamos la lectura de "Liberación del Trabajo", de Jorge F. Nicolai.-Edt. Americalee.-Buenos Aires.-1941.

(2).-_Nociones elementales de Derecho del Trabajo"._Edt. Nascimento. Santiago de Chile.-1941.

(3).—"Tratado elemental de Derecho Social"._-Madrid._1934.

(4).-_"Derecho del Trabajo”.-Buenos Aires.

(5).-Clasificación que hace Héctor Escríbar Mandiola en su monografía intitulada "El Seguro contra el Paro Forzoso".-Universidad de Chile.-Cuadernos Jurídicos y Sociales XIII.

(6).-Francisco Walker Linares.-Ob, cit. 